\title{
Feasibility Study on Forming Tennis Club of College Student
}

\author{
Xiying Zuo \\ Department of Sports, Henan University of Traditional Chinese Medicine, Zhengzhou City 450000, \\ Henan Provence, China
}

\begin{abstract}
As a new type of sports, tennis sport attracts more and more attention to students. Due to the impact of venues and facilities, curriculum, quantity of professional teachers and so on, the enthusiasm and interest of learning tennis is further hampered. The establishment of College Student Tennis Club will be able to effectively combine tennis teaching and extracurricular tennis, to give full play to its advantages in resources of colleges and universities, providing conditions to teachers and students for the orderly conduct of tennis activities and tennis cultural communication, to meet the needs to learn the technology of tennis and improve the skills of tennis of college students, contributing to the popularity of tennis in colleges and universities.
\end{abstract}

Keywords: College; college students; Tennis Club.

\section{Introduction}

With the continuous deepening and development of colleges and universities to quality education as the goal of sports reform, there have been many universities teaching in the form of sports clubs. The conducting of Student Sports Clubs good mobilize the enthusiasm of students to learn and participate in sports. Because of its elegance, fashion and sports properties, tennis is loved and participated by many college students. Now tennis as a semester elective classes in the Non-PE Majors and as one to two years of specialized course in PE majors. As can be seen from tennis technical characteristics of the movement, the teaching time is relatively short, and students practice time is lack, resulting in when most of the students just to master the basic essentials, but the technical term is over. So the students are interested in learning often feel that the increasing is limited. Therefore, students can not be met only rely on curricular sports teaching. The only form of developing and promoting tennis in college is that combine curricular teaching and extracurricular activities effectively. Practice has proved that, organize learning and training in the form of extra-curricular sports clubs, making extra-curricular sports activities and sports classroom teaching with interactive, providing a place and good sports atmosphere for college tennis event and improving the students' skills. Meanwhile meet the need of developing and promoting tennis in Universities, and promote the overall development of college tennis.

\section{The advantages of establishing extracurricular tennis club in Universities}

\subsection{Good sports culture}

Universities is diversify. It contains more extensive contents, more intense sports culture, and make sports communication, collection more quickly, thus building college tennis club has a good foundation. It is well known more active learning environment in universities, and students have more spare time, so many students put their spare time to devote to sport. Because they think that the exercise can not only ease the pressure of learning, but also is a good form of entertainment. Tennis is a new fashion sport, which combines features of sport and the fashion flavor. It is also a variety of fashion movement pursued by leisured. It is so better to stimulate students love it.

\subsection{Better tennis facilities and professional tennis teacher}

Tennis is a sport demanding high quality venues and equipment. Because of better equipment, venues and facilities, it enables to make tennis's favorite of students to the reality in university. In addition, college students contact more with society, and have a certain understanding for the development of society, which play a catalytic role on training students' hobby. On the other hand, 
university teachers' professional knowledge is more comprehensive, which has a greater help on training the level of tennis of college students. So carrying out extracurricular Tennis Club have a greater advantage in colleges and universities.

\subsection{Spare time of school students and limits of subject setting}

Students have plenty of spare time. They can self-governed more time with less stressful learning, and students have more time and energy to research theory and technology tennis studies. But in the process of teaching, public school sports majors are implementing a semester elective classes, and their teaching time is shorter. So students have less training time. Conducted Tennis Club after school not only meet the needs of students, but also enrich the cultural life of the school, and promote the healthy development of tennis in college.

\section{Necessity of formed College Student Tennis Club}

\subsection{In favor of sport to inspire students' motivation and inspire the enthusiasm of students to exercise}

Contents of Physical Education in University are in accordance with the requirements of the syllabus, and it is relatively simple and easy to lose interest for students; The teaching time is short on curricular tennis for students, and they often feel having less exercise time. So it is difficult to grasp the action essentials. And the formation of the tennis club not only makes the desire to exercise of the students are met, but also overcomes the single teaching contents and other adverse effects, and the majority of tennis fans get scientific and effective training to further improve the students' enthusiasm for tennis, laying a good foundation for students to participate in sports motion lifelong.

\subsection{Universities may make Tennis Club as a breakthrough Socialization Reform in Colleges of Sports}

Currently, the college sports reform have hot scene. Domestic experts and scholars agree that college students should complete curricular and extracurricular organic combination, thereby reducing the gap between school teaching and community. Teaching should be playing a good foundation on future employment, work and life for students. Since the tennis club has its own business and consumer society, students in the learning process can be closely related to the use of community sports and social resources, improving students' understanding and awareness of society; in addition, the tennis club also held to promote a sense of crisis of student employment, to urge more independent learning for the students; School can also be used as a breakthrough of Socialization reform in Colleges of sports, so that students can closely combined with community by holding the the tennis club, training more tennis talent, improving the overall quality of students and making social foundation on development of university sports reform.

\subsection{Mobilize the enthusiasm of PE teachers}

PE teachers work mostly motivated by the society and the degree of attention of the school's decision. Currently, there are still appeared low pay, low social status, and so on for the PE teachers in some schools, which has a certain extent dampened on the enthusiasm of teaching for PE teachers. Due to lack of investment in school sports training, the object of School physical education at this stage can not be very good for training. And the formation of after-school tennis club overcomes the problem of insufficient funds. The students involved in the process at the same time have a fair price and recognize the teachers' efforts. It improve the status of PE teachers in the minds of students, inspire teachers' enthusiasm for teaching, and mobilize the enthusiasm of teachers' work.

\subsection{Promote the popularization and development of tennis}

At this stage, tennis facilities is inadequate, with less organized tennis tournament, and fewer extracurricular activities in university, resulting in many students learning tennis is unfinished, which inhibits popularization and improvement of the tennis in Universities. Universities should establish 
tennis club, the more responsible students or teachers have the responsible efficacy, and further promote the role of tennis, to attract more students to participate. Meanwhile develop a scientific and effective management system and training methods, timing hold of various forms tennis teaching and tennis matches, and improve the students' level of tennis continuously. It is the only way to help promote the popularization and development of college tennis in China.

\section{Question in the conduct of Tennis activities in University Tennis Club}

\subsection{Few learning opportunities and lack of driving range}

Compared to the United States and Europe, tennis to carry out relatively late in our country, so professionals are still relatively lack. Most engaged in teaching tennis teacher are tennis fans in many colleges and universities. They have not received professional learning and training, and are not very professional in teaching organization; tennis technique is difficult to master and takes a long time to study. Many students who interested in learning have a slow progress in learning tennis and lose confidence after study for some time; when tennis requires good venues and facilities for protection, and most of the tennis courts in universities very is lack, resulting in the practice of most students can not be effectively guaranteed and student's skill level can not be improved for a long time, and further affect the enthusiasm of students to learn tennis.

\subsection{College Physical Education Teachers' lack in Tennis Teaching}

From the current state of development of college tennis, more and more students participate in tennis. Because the technical operation of tennis is not easy to grasp, and the raising level is a long process of accumulation, leading technology and skills of the participants is poor, which have higher expectations on the professional knowledge and teaching ability of teachers. Therefore, a certain amount of training and the introduction of professional tennis teachers are key to the development of universities tennis. At the same time, we need to improve the existing level of professional knowledge and operational capacity of tennis teachers, and continuously improve the quality of teaching, promoting the smooth development of college tennis.

\subsection{Experiencing on "high consumption characteristics" of the problem undertaken in tennis Universities}

Tennis has always been considered as a "noble sport", and it is mostly limited to school teachers and students in the "noble" group participate in universities, which suppresses tennis movement in the College. A lot of students who want to participate is prohibitive, which has a great relationship in characteristics of the tennis, such as "fashion" and "consumption". College Students belonging to consumer groups with the fixed costs, so there are too many limitations in tennis with respect to basketball, table tennis and other sports, which limits the college students' enthusiasm and motivation for learning in a large extent. Combined with consumption situation of college students, if we want to make tennis develop faster and better, we need to reduce the level of consumption of tennis. So that most students can accept their consumption levels, which has direct impact on promoting the development of college tennis.

\section{Countermeasures of Developing College Tennis Club}

\subsection{Raise the awareness of the sport of tennis of college Students}

Do effective publicity and promotion to tennis through a variety of effective ways and means. Schools can take advantage of the tennis club Newspaper, windows, television, multimedia and other modern means to organize students to watch a variety of tennis game, so that students exposure to the atmosphere of the tennis, and tennis enhance students' feelings; students enable to understand the value and role of tennis through advocacy, attracting more students to participate in tennis, to allow students to find happiness from tennis. They make tennis gradually as part of life, and cultivate students awareness of lifelong participate in tennis. 


\subsection{The development of relevant teaching objectives and tasks}

University Tennis Club is built to enrich students' extracurricular sports activities, create after-school sports environment for the majority of sports fans. It is a kind of extra-curricular activities organization, which is adding the teaching process of teaching content to the club curriculum, to make up the classroom lack of education, so that students have more practice time. Thus, a tennis club should be carefully to develop a scientific and effective teaching objectives and teaching tasks, and continuously improve the quality of teaching and tennis skills of student.

\subsection{The development of scientific and effective management system}

It has a direct relationship between development of the tennis club and the club's management system. If the development of management system is more scientific, and management ability of manage personnel is high, operation of the club will be able to develop along a healthy and effective direction. And enthusiasm of the teachers' teaching and students learning is high. Meanwhile technical level of students in tennis will continue to increase, which has a positive impact on the conduct of college tennis.

\subsection{Make efforts to broaden the channels of funding sources}

To increase the popularity and development of college tennis, tennis club must ensure that activities are funded. Formulate corresponding measures for school sports underfunded features to ensure economic sources. Such as: club membership dues, school sports funding support, support for the Communist Youth League school or student activity funds, the support of social sporting goods store and school leadership funding support.

\section{Conclusion}

Tennis has its own unique charm in college, and it is loved and participate by many college students. Therefore, the university should increase financial investment, construct a number of tennis venues, solicit professional tennis teacher, and take a scientific and effective form of organization to carry out teaching and coaching tennis. It is proved that the form of the establishing college tennis club is the most effective, and it is welcomed by the students, which make physical education curriculum teaching combining to extracurricular physical exercise, further play the main role of students to fully mobilize the students' initiative and enthusiasm.

Establishing University Tennis Club can make college sports reform going along the road of quality education in healthy and orderly development forward, which can effective cultivate lifelong physical culture consciousness of college students. Students master the skills and methods of lifelong physical exercise, participate in physical exercise continuity, and comprehensively improve the overall quality of students.

\section{References}

[1] Wei-Juan Zhou. Feasibility Study on the establishment of extracurricular Tennis Club. Anal Science and Technology, June 2011.

[2] Qiao-Ling Li. College tennis club development. Sport Science \& Technology, April 2014.

[3] Hai Huang. Guangxi University Sports Clubs Situation and Development Strategy. Guangxi University of Technology, 2015. 